\title{
Psychological Issues for Patients Undergoing Stem Cell Therapy and Regenerative Medicine
}

\author{
Natasha Braunsteiner ${ }^{1}$, E. Russell Vickers ${ }^{1,2,3 *}$, Rachel Shparberg1,4 \\ ${ }^{1}$ Clinical Stem Cells Pty Ltd., Sydney, Australia \\ ${ }^{2}$ Department of Anaesthesia \& Pain Management, University of Sydney, Sydney, Australia \\ ${ }^{3}$ Clinical Research Center, Combak Hospital, Hangzhou, China \\ ${ }^{4}$ School of Medical Sciences, Discipline of Physiology, University of Sydney, Sydney, Australia \\ Email: ^manager@clinicalstemcells.com
}

How to cite this paper: Braunsteiner, N., Vickers, E.R. and Shparberg, R. (2018) Psychological Issues for Patients Undergoing Stem Cell Therapy and Regenerative Medicine. Open Journal of Regenerative Medicine, 7, 1-17.

https://doi.org/10.4236/ojrm.2018.71001

Received: February 5, 2018

Accepted: March 27, 2018

Published: March 30, 2018

Copyright $\odot 2018$ by authors and Scientific Research Publishing Inc. This work is licensed under the Creative Commons Attribution International License (CC BY 4.0).

http://creativecommons.org/licenses/by/4.0/ Open Access

\begin{abstract}
Stem cell therapy is a relatively new treatment modality in the field of regenerative medicine. The therapy is gaining increased awareness and acceptance by the public. There are multiple factors that contribute to a stem cell procedure for regenerative medicine in order for it to be successful. One of these factors is a patient's mental health and psychological state. The role and significance of a counsellor/psychologist will be examined as a crucial part of the regenerative medicine team. Pre-existing issues of depression, anxiety, post-traumatic stress disorder (PTSD), addiction, low self-esteem and high levels of stress could adversely affect outcomes. For example, fears and phobias are counter-productive for planned regenerative therapy. The counsellor must also assess and determine that the patient is mentally and psychologically healthy. In addition, advice is necessary for the patient to have realistic expectations in order for them to be eligible for treatment. Some patients are not suitable for stem cells and other regenerative procedures until psychological treatment is successful, particularly in body image dysmorphia. A comprehensive psychological assessment is needed and answers must be provided for patients by the counsellor during all phases of the treatment.
\end{abstract}

\section{Keywords}

Stem Cells, Regenerative Medicine, Counselling, Psychology, Mental Health, Depression, Anxiety, Stress

\section{Introduction}

Stem cell therapy is a relatively new treatment approach for medical conditions involving regenerative medicine. Emerging evidence demonstrating safety and 
efficacy is providing further impetus for clinicians and their patients to consider cell based therapies. One developing area is stem cells for treating chronic pain conditions such as osteoarthritis and neuropathic pain. However, a number of psychological issues continue to arise from patients receiving stem cells, for example, patient enquiries about the potential of stem cells to cause cancer and genetic mutations being introduced into a host patient from allogeneic cells. Furthermore, the simple injection of stem cells, local anesthetic and saline for tumescent liposuction in the case of adipose derived stem cells can still initiate extreme anxiety in a needle phobic patient. Consequently, the presence of co-existent negative psychosocial variables with the medical condition to be treated can significantly impact patient outcomes as in the case of improving chronic pain states. The gold standard approach to medical treatment is a multidisciplinary assessment of medical, psychological and physical factors, termed a biopsychosocial paradigm. Chronic pain is one of the key reasons for the public to investigate stem cell therapy as the current conventional approach utilizes medication including antidepressants and anticonvulsant drugs. However, these drugs such as amitriptyline, pregabalin and gabapentin have a relatively poor outcome ratio when comparing the number needed to treat (NNT) of 1:3-8 with the number needed to harm (NNH) of 1:2

(http://cochranelibrary-wiley.com/cochranelibrary) i.e. the public are twice as likely to incur adverse drug side effects compared with pain reduction. This is of particular concern to patients as possible drug side effects include significant weight gain, drowsiness, paradoxical depression and anxiety, alopecia, skin rash, increased suicidal ideation and peripheral neuropathy. Moreover, drug tolerance, drug interaction and addiction to opioid medication are ongoing worrying issues for the medical doctor. Alternative cell based therapies are an attractive option when safety and efficacy have been established for the individual patient and the treating doctor. Moreover, governments are increasingly concerned due to the prevalence and high socioeconomic burden of pain.

The rise in cosmetic medicine is one further increasing trend where stem cells are used despite the paucity of evidence [1]. The purpose of this article is to illustrate various potential psychosocial issues that may develop in the clinical phase that are specific to stem cell therapy. To the authors' knowledge, this is the first article to list patient concerns of stem cell therapy and provide a framework of evidence based treatments from other established areas of medicine. The chronic pain model is used to list potential psychosocial issues due to the increasing use of stem cells as a treatment. The authors are core members of dedicated clinical stem cell team performing this therapy with combined $20+$ years in stem cell training, research, treatments and publications. NB specializes in counselling and the psychological assessment of patients undergoing stem cell therapy, RS is a developmental cell biologist with extensive laboratory research in stem cells, and ERV is a surgeon who specializes in treating patients with autologous mesenchymal stem cells with publications in this field. 
The comprehensive assessment of psychological issues of the patient is an imperative component to consider by the clinician for any treatment. This involves discussing with the patient their unresolved past issues, current problems and identifying potential future aspects that could negate treatment outcomes. Stem cell therapy holds a unique position in this regard. Autologous stem cell therapy is considered a safe and highly valued treatment for use in pediatric leukemia patients since its institution in the 1980s. Positive exposure from media sources for its use is underpinned by extensive medical research publications. This generates confidence in the public domain for its use in other medical conditions. However, in any treatment there are possible complications and risks that can and do arise. Even in rare circumstances, a complication can generate extensive negative media to the public and consequently with the loss of confidence, and increased individual stress and anxiety for a prospective patient should stem cells be considered. An example of this occurred when stem cells were injected into the face of a patient for cosmetic reasons and minor bone splinters developed around the eyelids that were simply removed. The patient had previous injections of hydroxyapatite filler from another surgeon that coaxed the stem cells to differentiate to osteoblasts instead of fibroblasts. The response from certain media outlets was to create a sensational headline for the public using terms such as "Botched, gruesome, bone fragments grinding against each other" (Figure 1).

The importance of allaying this type of anxiety is necessary for successful outcomes. Stem cell therapy is a new treatment modality for most medical doctors and allied health practitioners such as dentists. Their role is supported by the use of counsellors and psychologists to achieve a successful "human" outcome rather than a simple "physiological improvement of the disease". For example, in the area of chronic pain, the biopsychosocial approach provides an excellent framework of multidisciplinary assessment for stem cell therapy. Simply reducing pain intensity in a chronic pain patient without treating depression, anxiety, stress and an addiction to prescription drugs leads to failure. Treating the psychosocial disease is as important as the medical treatment.

In the case of allogeneic stem cells further anxiety and many questions from the patient is likely to occur. This is no different when considering drugs with potential side effects such as weight gain, sedation, drowsiness and hair loss from frequently used tricyclic antidepressants for neuropathic pain. Moreover, the list of side effects from other drugs include acne, loss of libido, suicidal ideation, gastric ulceration, lethargy, impaired renal and liver function, blindness

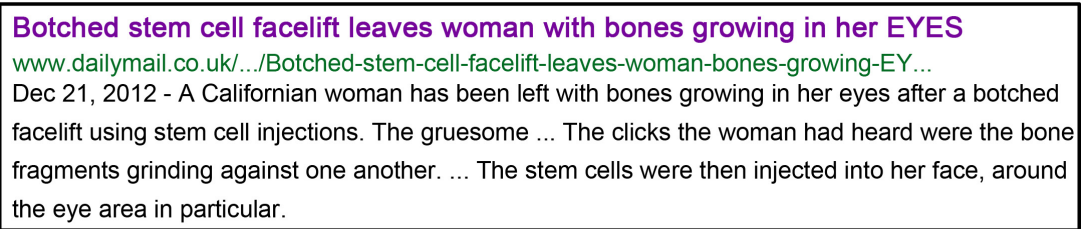

Figure 1. Internet headline of a complication from stem cell treatment to the face. 
and hearing loss. The purpose of this article is to outline, identify and indicate the treatment approach for the numerous psychosocial variables that are likely to arise when the clinician is providing stem cell treatment.

\section{Explaining Basic Scientific Principles of Stem Cells to Patients}

Stem cell and regenerative therapies have received much attention over the years for their potential to rejuvenate and repair damaged and aged tissue. The field of stem cells is rapidly evolving and as technology improves, so too does the prospect of treating a variety of conditions. However, it is important to appreciate that the field of stem cell therapy and regenerative medicine is still emerging, and there is much to learn about how stem cells interact with their environment to repair damaged and diseased tissue. As previously shown in the media (Figure 1), negative comments undermine the true therapeutic benefit of stem cells. An explanation of stem cells from their origin, different types and donor sources (autologous or allogeneic) helps reduce uncertainty and anxiety about the nature of the planned treatment. The following outline is provided for the clinician to help the patient in understanding the basic principles in stem cell therapy.

A stem cell is a unique cell that, unlike normal body (somatic) cells, is 1) capable of self-renewal over extended periods of time (i.e. it is able to stay as a stem cell over multiple cell divisions) and 2) maintains a level of potency (i.e. an ability to differentiate into another type of cell when the conditions are favorable). There are four main types of stem cells that patients may be aware of including embryonic, adult, induced pluripotent and cancer stem cells. It is therefore imperative to explain the nature of therapeutic stem cells from cancer stem cells to a patient to prevent anxiety and stress from a lack of knowledge. Embryonic stem cells are those derived from the early embryo. These cells are pluripotent, which means that they are capable of differentiating into any of the cells that make up the structural and physiological components of an adult, and support foetal development. For ethical reasons embryonic stem cells are rarely used for treatments. Adult stem cells are multipotent in nature, which means that they are capable of restricted differentiation into cell types within their lineage of origin: For example, neural stem cells can differentiate into neurons and glia of the central and peripheral nervous stems, but have lost the ability to form, for example, skin cells. Induced pluripotent stem cells are derived from somatic cells that, in theory have lost the ability to differentiate, but are reprogrammed back to an "embryonic stem cell-like state" (Figure 2). Cancer stem cells are those derived from tumours that have the ability, like a healthy stem cell, to self-renew and differentiate, and often form the basis of cancer development in patients. For a review of each type of stem cell see Batlle et al. [2].

Stem cell therapies in several countries can be administered to a patient provided that they are autologous in nature (i.e. the cells are derived from the patient and re-administered back to the same patient), the cells are minimally 


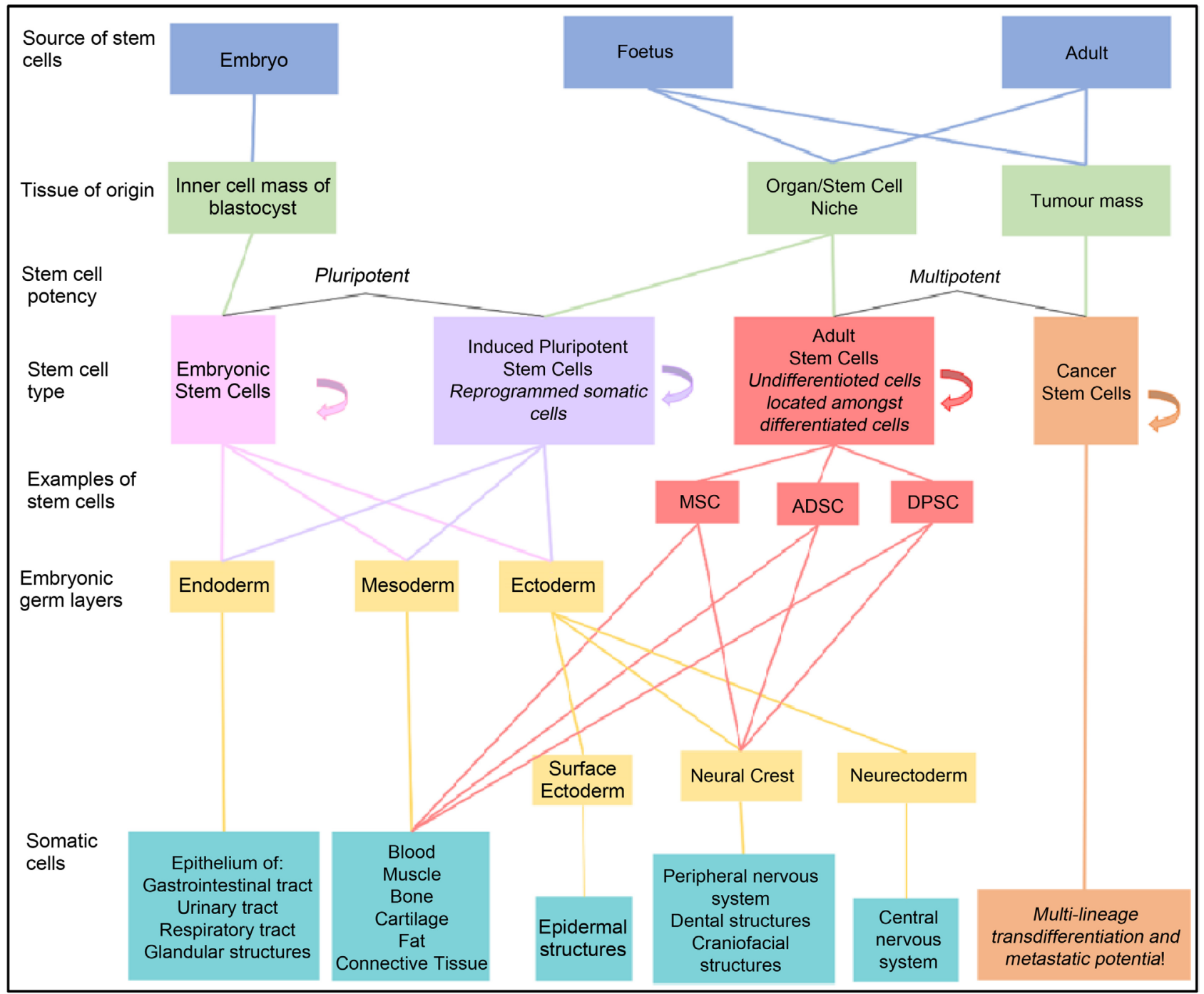

Figure 2. Derivation, types and differentiation potential of pluripotent and multipotent embryonic-, foetal- and adult-derived stem cells. 1) Embryonic stem cells are derived from the inner cell mass of the early blastocyst-stage embryo and can differentiate into all somatic and germ-line cell types that form the human body from each of the three multipotent definitive germ layers (endoderm, mesoderm and ectoderm). Stem cell therapy using embryonic stem cells is currently not permitted in many countries. Rather, these stem cells are predominantly used for understanding the molecular mechanisms underlying embryonic development and cell differentiation. 2) Induced pluripotent stem cells are those that are derived from mature cell types (for example, skin cells) and are reprogrammed back to an embryonic stem cell-like state. Once reprogrammed, iPSCs can then differentiate into somatic cells of each of the definitive endoderm, mesoderm and ectoderm germ layers. iPSC technology has yet to efficiently progress to the clinic, however, there is the prospect that this technology will be the face of personalized regenerative therapy in the future. 3) Adult stem cells are multipotent cells that are derived from stem cell niches in foetal and adult organs and tissues. Some examples include: mesenchymal stem cells (MSCs), adipose-derived stem cells (ADSCs) and dental pulp stem cells (DPSCs). These cells are conventionally restricted to differentiating into cell types from their lineage of origin. For example, MSCs are derived from the mesoderm lineage, and can therefore differentiate into cells of this lineage. DPSCs are derived from the neural crest lineage and can differentiate into a range of craniofacial structures including muscle, bones, peripheral nervous tissue etc. Currently, autologous cell therapy using adult stem cells (derived from the patient and delivered back into the patient) are at the forefront of therapeutic and regenerative medicine. 4) Cancer stem cells are unique cells located within tumours that possess similar characteristics to normal stem cells: They can self-renew (curved arrow), but unlike normal stem cells, cancer stem cells are genetically unstable and therefore self-renew and proliferate uncontrollably, often transdifferentiating into a mix of different cell types from different cell lineages, as well as being able to metastasize under appropriate conditions. 
manipulated and the entire procedure is performed by or under the supervision of a clinician. Not all conditions are considered proven therapies yet. In fact, to date, only certain blood, skin and vision stem cell-based treatments have been approved and are recognized as safe and efficient treatments, as per rigorous clinical trial results. Nevertheless, conditions such as arthritis, degenerative conditions, autoimmune disorders and chronic pain are showing promising results from stem cell therapies, particularly from a type of adult stem cell known as a mesenchymal stem cell (MSC). These therapies however are still under scientific investigation and are thus not routinely offered as medically-approved therapies. This frustrates patients, as many of these innovative therapies have shown promising results, but the therapies are expensive and difficult to gain access to. At the same time, MSCs are often advertised as the "cure all" stem cell, misleading patients and medical practitioners and thus shaping wrong perceptions of stem cell therapies. It is therefore necessary to provide patients and medical practitioners with information regarding both the benefits and limitations of stem cells and associated therapies.

\section{Unrealistic Expectations and Perceived Failure of Treatment}

It is imperative that an initial psychological consultation with a patient is conducted before any procedural treatment such as tissue harvesting for stem cells and the re-administration of the manufactured product containing isolated stem cells. Most research conducted on the expectations and satisfaction with treatment has been qualitative, using psychometric instruments and questionnaires to investigate different types of expectations [3]. Ryan et al. [4] conducted a dental study to measure treatment expectations and their results showed that multiple physical improvements were expected of both increased function (correct occlusion for mastication) and improved esthetics ("straight teeth"). Positive nonphysical (psychological) changes from an anticipated good physical outcome that were expected included an improvement in emotions, patients were expecting to be happier, more confident and relaxed and that the thought of treatment was positive as it would aid their current perceived defects of misaligned teeth. Not surprisingly, psychological expectations about changes in appearance ranged from wanting to be normal to expectations of wanting to be perfect and unrecognizable. The study showed patients had a desire to become a better version of themselves and that treatment would be able to achieve this. The preliminary psychological analysis before treatment should evaluate all areas of the patient's life [5]. It is not uncommon for some patients to present with unrealistic expectations and thoughts and the role of the counsellor/psychologist is to change negative undermining thoughts of "needing $100 \%$ cure or perfection" to more realistic healthy expectations. Verbal and written questions allow both clinician and patient the time to list and respond to possible difficulties of a personal nature [6]. A standard set of questions can be given and then further in 
depth time allocated where patients may present with their own set of questions. For cosmetic stem cells, idiosyncratic thoughts and even photos of what they wish to look like should be viewed by the clinician. It is imperative the counsellor address these types of thoughts and the areas of concern should be rechecked prior to stem cells. The role of the counsellor is to confidently reply to the common questions, solve evolving issues of worry and assess the individual needs of each patient through qualitative analysis [7].

Financial issues can be an important area for the counsellor to discuss with each patient. Stem cell therapy in most countries relies on the patient to pay for the treatment as it is a new therapy that governments and health insurance providers have yet to acknowledge for monetary reimbursement. Subsequently the expense, often high, incurred by the patient may cause similar high expectations from the therapy. Timely and prudent advice from the clinician to the patient should be given regarding a realistic outcome. Another situation is where the patient judges their own autologous stem cells as a "natural therapy" and s/he is more likely to be compliant in pre- and postoperative care information.

\section{Assessing Depression, Anxiety and Stress}

The psychological assessment of the patient considering stem cell therapy is an important component in the clinical work up. Depression, anxiety and stress are variables that can dramatically inhibit treatment outcomes. A simple, non-invasive and accurate tool for measuring the psychological profile is through the use of a questionnaire such as the depression, anxiety and stress scale (DASS-21). The DASS-21 is a well-established instrument for measuring depression, anxiety and stress with good reliability and validity [8]. The DASS-21 was developed to measure the constructs of depression and anxiety and to address the failure of early emotional measures in discriminating between anxiety and depression [9]. It is an economical pencil-and-paper instrument and reduces administrative time by taking five minutes to complete and has been widely used in clinical environments. The DASS- 21 is provided by counsellors and psychologists during a structured clinical interview [10]. Since its publication in 1995 the DASS-21 has been used in numerous types of research such as early life stress and adult emotional experiences, chronic and acute pain patients, addictions and mental illnesses [11]. The patient should have baseline results recorded prior to treatment and then be repeated at regular post-surgery intervals. This will help the clinician to monitor the patients' mental and psychological state during the entire course of therapy and record how the patient is coping with the phases of stem cell rehabilitation where improvement can take several months to achieve meaningful and visual improvement (Table 1).

\section{Psychological and Psychiatric Patient Profiles as Exclusions for Stem Cell Therapy}

A psychological assessment should be performed during the first phase of the 
Table 1. Description of psychological terms that can be involved in stem cell therapy.

\begin{tabular}{|c|c|}
\hline Psychological Term & Description \\
\hline Depression & $\begin{array}{l}\text { Pain can bring on depression which can affect the patient in multiple } \\
\text { aspects of their life. It is common for the depression to be a } \\
\text { secondary symptom of the pain, and by reducing the pain intensity } \\
\text { then the depression subsides. Symptomatic depression can be } \\
\text { treated in the same way as general depression as it effects the patient } \\
\text { in the same way. Symptoms of depression include a change in } \\
\text { appetite, fatigue, a sense of worthlessness, sleep problems, } \\
\text { loss of motivation, and feeling sad and withdrawing. }\end{array}$ \\
\hline Anxiety & $\begin{array}{l}\text { Anxiety can affect a patient in quite a physical way from } \\
\text { increased heart rate, rapid breathing, perspiration, } \\
\text { panic attacks, tightening of the chest, tremors and shaking. }\end{array}$ \\
\hline Stress & $\begin{array}{l}\text { Stress can affect all aspects including emotions, behavior, thinking } \\
\text { ability and physical health. No part of the body is immune but } \\
\text { because people handle stress differently, symptoms of stress can vary. } \\
\text { Stress is a common issue observed in patients with chronic pain and } \\
\text { the higher the stress, the higher the pain intensity score. }\end{array}$ \\
\hline $\begin{array}{c}\text { Post-Traumatic Stress } \\
\text { Disorder (PTSD) }\end{array}$ & $\begin{array}{l}\text { It is common for a patient to experience PTSD and persistent pain as } \\
\text { co-morbidities. The patient may fear doctors, dentists, professionals, } \\
\text { medical and surgical procedures that can increase pain. In addition, } \\
\text { pain can trigger the PTSD and can cause avoidance, nightmares, flash } \\
\text { backs, and increased stress and anxiety levels. }\end{array}$ \\
\hline Addiction & $\begin{array}{l}\text { Patients seeking stem cell therapy may have an addiction, for } \\
\text { example an excessive and frequent consumption of pain medication. } \\
\text { A further addiction in pain patients is inappropriate drug use as a } \\
\text { method for escape and distraction. The patient begins to } \\
\text { self-medicate using alcohol, prescription drugs, and illicit drugs } \\
\text { such as cocaine and cannabis. }\end{array}$ \\
\hline $\begin{array}{l}\text { Body Dysmorphic } \\
\text { Disorder (BDD) }\end{array}$ & $\begin{array}{l}\text { Body dysmorphic disorder is preoccupation with one or more } \\
\text { perceived defects or flaws in his/her physical appearance that are not } \\
\text { observable or appear slight to others. At some point during the } \\
\text { course of the disorder, the individual has performed repetitive } \\
\text { behaviors, for example mirror checking, excessive grooming, skin } \\
\text { picking, reassurance seeking behavior and continually comparing } \\
\text { his/herself with that of others. This preoccupation can cause } \\
\text { significant distress or impairment in the social, occupational, } \\
\text { or other important areas of functioning. However, } \\
\text { preoccupation in this context does not concern body fat or weight. }\end{array}$ \\
\hline Suicide & $\begin{array}{l}\text { In terminal disease states and chronic pain there are increased } \\
\text { suicidal tendencies. It is important that a suicide risk } \\
\text { assessment is performed with these patients. }\end{array}$ \\
\hline
\end{tabular}

stem cell consultation process, along with the medical check list for patient suitability. During this consultation the counsellor should carefully observe patient behavior and listen to their answers from a set of specific questions focused on all aspects of their mental and psychological state. There are several patient profiles that either potentially exclude patients, or requires intensive therapy prior to the treatment phase. Patients with conditions such as uncontrolled schizophrenia, bipolar disorder, post-traumatic stress disorder (PTSD), depression, anxiety, anorexia, body dysmorphic disorder and addiction should not be consi- 
dered eligible for stem cell treatment [12]. In addition, high levels of stress or constant background stress, although prevalent in society, may prevent a successful outcome. PTSD patients may need long term psychological treatment with an extended timeframe before they are eligible for stem cells. The doctor and psychologist jointly need to be satisfied that the patient is ready for the stem cell intervention (Figure 3).

\section{Fear and Apprehension from Stem Cell Therapy}

Several fears about stem cells may trigger apprehension of the proposed treatment. Typical questions asked by a patient can be "what if I am given another person's stem cells with unknown DNA mutations" or "I am worried I may get cancer from stem cells". These are real concerns and the stem cell team comprising doctor, psychologist and stem cell scientist must provide a clear understanding of the relative risks of all aspects of treatment. The doctor must provide procedural risks such as swelling, pain and discomfort, prolonged bleeding and risk of post operative infection from the donor site. The psychologist advises the patient of realistic goals and outcomes, and techniques to rebut stress. The stem cell scientist reassures the patient that extensive laboratory validation tests are conducted on the cells to confirm cell viability, cell numbers and stem cell $\mathrm{CD}$ markers.

As stem cell therapy is a relatively new procedure it is likely that multiple fears and concerns would be brought forward by presenting patients. Further

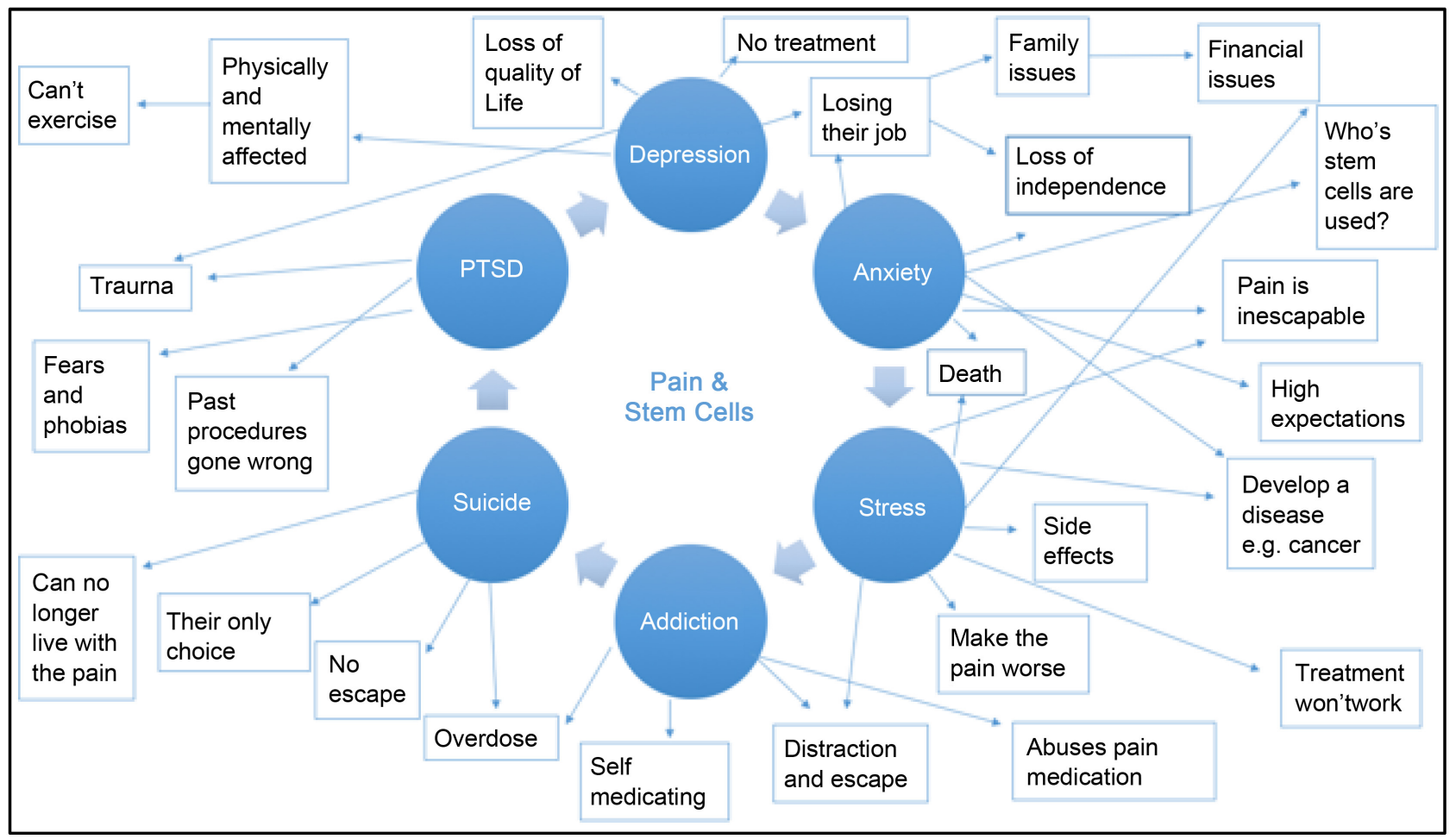

Figure 3. Psychological aspects of stem cell therapy for therapeutic treatment using a chronic pain model. The network map demonstrates the complex interconnectedness of psychosocial variables when treating a medical disease. 
reassurance should be given that government legislation in most countries places a high emphasis on safety from medical procedures, medical devices and drugs used for treatments. Higher levels of safety and reassurance are met when using autologous stem cells as there is no risk of cell rejection and this information should be explained. In the case of allogeneic cells then a higher level of potential risk should be openly discussed with the patient and the "significant other" (partner, relative or friend). Providing published high quality research articles demonstrating safety can dispel unfounded fears. In addition, the medical doctor should conduct blood screens on patients to determine if there is any risk from the patient such as transmissible disease to other patients or clinic staff. Some patients will question the sterility of instruments used. Providing evidence of a validated sterilizer or using disposable single use instrument packs will reassure the patient.

\section{Cancer and Stem Cells}

As mentioned above there are strict and thorough initial tests and screening that takes place before the stem cell treatment. However, in the unlikely event that the screening tests are not performed or validated then the patient can possibly receive stem cells from a diseased site or unknown donor, thereby posing a potential risk of developing a disease or illness. Like any situation where blood and/or bodily fluids are shared there is a risk of developing a complication. Moreover, where recipient sites contain autologous or allogeneic cancer stem cells then the risk can be magnified due to stem cell expansion (increased cell number) and the migration of stem cells potentially causing metastatic spread [13]. Cancer contains cancer stem cells, and poorly differentiated cancer cells can increase in number quickly. One of the key contraindications to stem cell therapy is untreated cancer. In patients with suspected cancer then thorough screening is needed with clinical tests, radiographic examinations, cancer biomarker assays and genetic testing for a risk evaluation.

\section{How to Manage the Desperate Patient Seeking Stem Cell Treatment}

Patients may catastrophize when given a diagnosis concerning conditions such as cancer, multiple sclerosis and motor neuron disease. These conditions have different levels of malignancy and disease severity. The treating clinician and psychologist should contact the patient's specialist to record the "real life expectancy" compared with a possible exaggerated report from the patient. When dealing with the desperate patient it is important that you acknowledge their emotions and feelings and that they feel heard and understood. It is essential that every patient is treated with respect, nonjudgment and made to feel comfortable no matter how trivial or simple the issue may be. Some patients may present with significant distress and desperation towards their health and may feel the only option they have to survive is the stem cell treatment. This is un- 
healthy and unrealistic thinking. It important that these issues are given a "red flag of urgency" and should be addressed during the first consultation. The patient may erroneously believe that stem cells will cure the disease despite the lack of published evidence. In addition, patients may incorrectly think that there will be a rapid reduction of their symptom profile and a dramatic enhancement of their quality of life [14]. Reassurance and providing a realistic timeframe of improvement will help the patient's quality of life and give back their independence [15]. Advice should be given by the clinician that the patient should be focusing on structured phases of improvement rather than the negative attitudes of dying.

In patients with chronic pain caused by a significant traumatic event then there is the likelihood of a PTSD co-morbidity. Significantly, the PTSD event may involve an associated medical situation of misdiagnosis, inadequate pain relief from surgery, malpractice of medical professionals, failed treatment plans, multiple pharmaceutical drugs that induced severe side effects such as suicidal ideations and the resultant constant temporal quality of "inescapable" pain. Moreover, breakthrough high intensity pain, and recurrent episodes can instigate a crisis where the patient demands stem cells for instant pain relief. Arming patients with the knowledge that stem cells are a long term biological treatment and not reminiscent of a rapidly acting opioid drug will prevent unreasonable demands on the clinician.

Past trauma, fears and the threat of death elicits extreme anxiety and stress that must be dealt with by psychological means - pharmaceutical drugs cannot treat or reduce affective pain dimensions of "fearful, punishing and cruel pains". It is important that the clinical team psychologist calm the patient and ensure they are safe and looked after. Identification and acknowledgement of a patient's emotional distress and negative thought patterns is crucial. The counselor by showing empathy and understanding with the patient will guide them through the emotional upheaval in a controlled and structured way to avoid potential self harm. In summary, both the physical and mental health of the patient is a priority. The patient must be in a clear, calm, positive and realistic mind frame before they can be eligible for the stem cell procedure. It is the role of the stem cell counsellor to determine and treat psychosocial issues and advise the managing team clinician as to when the patient is psychologically fit for the procedure.

\section{The Role of the Counselor/Psychologist in the Stem Cell Team}

The preferred clinical stem cell team should comprise various specialists with dedicated roles such as medical specialist, surgeon, stem cell scientist, nurse, doctor, counsellor/psychologist and additional allied health where appropriate such as dentist, physiotherapist and dietician. Each professional plays a large and important role within the team and are crucial to the stem cell procedure. It is advantageous of having a large and diverse team to answer all possible questions from the patient and family, reassure the patient that the team can deliver op- 
timal and safe care, and provide validated methods for stem cell laboratory procedures. The counsellor has a critical role to ensure that positive attitudes and stable mental health are incorporated by the patient at all stages of the treatment. Ongoing psychological support provides security for the patient that $s /$ he is the priority and the counsellor monitors and is available for the needs of the patient throughout the entire process. This ensures there is minimal risk of perceived treatment failure. The counsellor should also explain that stem cells are the beginning of a long term management plan and that supervision and care of the patient is not a one stage treatment. This framework of multiple professionals in the stem cell team is designed to meet comprehensively the needs of the patient, and specifically for the counsellor to maintain the confidence of the patient. Stem cells should be viewed as an option with all other treatments. Taken together the patient will have various consultations for the different types of treatments possible thereby allowing the patient the liberty and confidence of the appropriate decision.

A further advantage of having the stem cell counsellor is to treat patients with fears and phobias regarding the procedural or surgical aspects of stem cell therapy. For example, needle phobias are prevalent and found in $3.5 \%-10 \%$ of the population [16] and this type of procedure is necessary in administering the stem cells by the intravenous (IV) route or local administration. Reducing this phobia can be accomplished medically by anti-anxiety drugs, or IV sedation/general anesthetic. Psychological approaches include exposure therapy, cognitive behavioral therapy (CBT) and solution focused therapy.

\section{Cosmetic Use of Stem Cells and Body Image Dysmorphia}

Psychological screening is particularly important for patients seeking stem cell therapy for cosmetic reasons. The phenomenal increase in people seeking elective cosmetic surgery and minimally invasive procedures is well documented. Major reasons driving this interest is focused on an attractive appearance, younger looks, stamina, increased muscular attributes and enhanced body shape morphology [17]. The counsellor investigates to a greater depth the patient's personality, lifestyle and appearance. There is a specific emphasis on identifying unrealistic expectations and mental health issues such as depression, eating disorders and body dysmorphia.

According to the Diagnostic and Statistical Manual of Mental Disorders (DSM-V 2013) [18] the criteria and symptoms for body dysmorphic disorder is preoccupation with one or more perceived defects or flaws in physical appearance that are not observable or appear slight to others. At some point during the course of the disorder, the individual has performed repetitive behaviors for example mirror checking, excessive grooming, skin picking, reassurance seeking behavior and continually comparing his/herself with that of others. This preoccupation can cause significant distress or impairment in social, occupational, or other important areas of functioning. However, preoccupation in this context 
does not concern body fat or weight.

There may be a history of having multiple procedures such as Botox, fillers and face lifts as afflicted patients see flaws in themselves that no one else can see or simply do not exist [19]. Body image is a subjective, self-evaluation of appearance and it is a construct that includes affective, cognitive behavioral and perceptual features [20]. It can have a profound effect on an individual's self-esteem, mood, eating patterns and social interactions [21] with the result of requesting frequent but unnecessary surgery. Despite multiple cosmetic procedures the patient is unhappy, discontented and never satisfied [14]. Previous attempts of cosmetic surgery fail to achieve the expected outcome and can have a large impact on an individual's self-esteem and mental health, initially positive then in a negative manner [22]. A careful determination by the psychologist is needed to to advise the patient whether stem cell treatment will be beneficial or cause more psychological damage [23] (Figure 4).

\section{Case Studies}

Two case studies are presented to demonstrate the scope of potential psychological effects when using stem cell therapy. Both cases have been published in the media - the first case in public commercial media and the second case as a peer reviewed medical publication.

Case 1 - Stem cell treatment resulting in death

Stem cell treatment at a UK teaching hospital resulted in the death of four

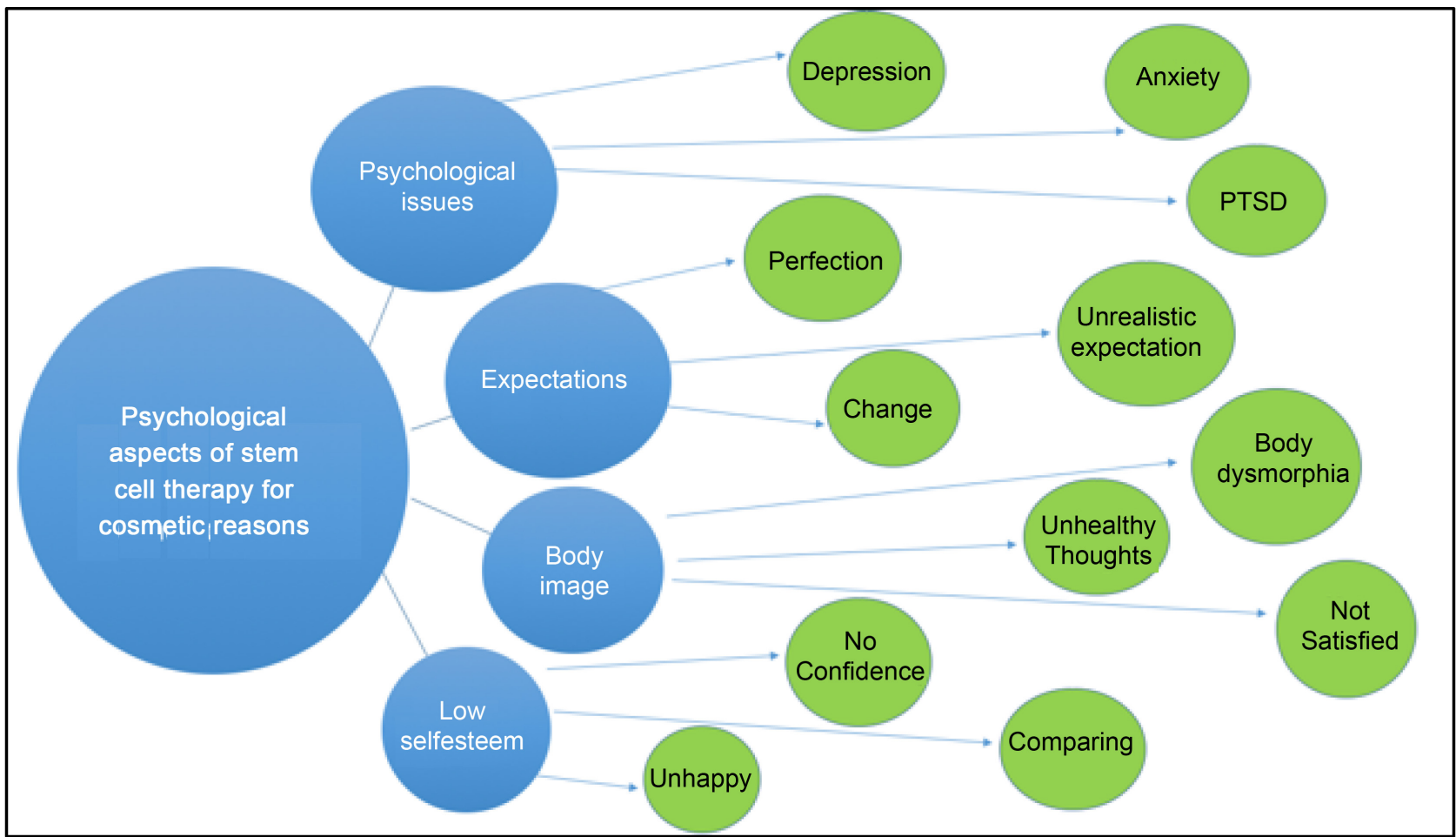

Figure 4. Psychological aspects of stem cell therapy for cosmetic reasons. The map demonstrates the signs and behavioral issues of psychological issues such as body dysmorphic disorder. 
children. It was reported in the public media that doctors at London's renowned Children's Hospital at Great Ormond Street were baffled when stem cell therapy routinely used to treat sick children with cancer inexplicably stopped working. The procedure was to reintroduce thawed bone marrow stem cells after chemotherapy [24]. Four of the children died from the procedure forcing the doctors to cease therapy as they were unsure what was the cause and what had gone wrong. The thawed stem cells underwent multiple tests for stem cell count (total number) and viability (individual cell survival). An independent expert determined that a crucial third test was not performed, namely the ability of the cells to proliferate and replenish depleted cells. The lack of thorough testing resulted in the deaths of four innocent children. Media exposure cast the stem cells as a negative and dangerous treatment, but human error was the cause.

This unfortunate event would have caused immense emotional and psychological trauma for the grieving parents and family members of the deceased children. The parents would have experienced a roller-coaster of emotions of disappointment, anger, guilt, blame, feeling distraught and sad. It would be natural for the parents and family members to feel betrayed and let down by the medical establishment, as they put their children in their care and trusted they would be safe and well looked after. Unfortunately, the outcome of planned survival resulted in unexpected death. This traumatic event could possibly destroy the parents trust and belief in all future medical treatments particularly stem therapy, in addition to the permanent loss of trust in hospitals, doctors and laboratory scientists.

Case 2 - Successful stem cell therapy (patient K)

$\mathrm{K}$ 's stem cell procedure has been extensively documented by the authors. $\mathrm{K}$ was a $27 \mathrm{yr}$ old female with a history of right sided cluster headache and trigeminal neuropathic pain. Multiple pharmaceutical drug treatments had been trialed but were ineffective or discontinued due to side effects. Botox had been injected several times into the right side of her face that initially provided pain relief. Subsequent injections showed declining efficacy and then caused neurovascular degeneration and significant right facial atrophy (Figure 5). $\mathrm{K}$ was then referred to the authors where she described severe pain and showed significant psychological distress. She described herself as being "unrecognizable", with low self-esteem and a poor quality of life. Psychological assessment identified severe depression and anxiety which lead to attempting suicide several times. She was unable to work complicating her problem.

$\mathrm{K}$ underwent autologous stem cell therapy that showed substantial pain reduction in the months that followed. Her pain intensity scores on a numerical rating scale (" $0=$ no pain, $10=$ worst pain imaginable") at baseline were 8 $10 / 10$, then $5 / 10$ at 1 month post-treatment and this further reduced to $2 / 10$ at 4 months post-treatment. The primary aim was a reduction in pain but there was clearly a noticeable cosmetic improvement in the face at 1 month and significant regeneration at 4 months. There were no side effects or complications with the 


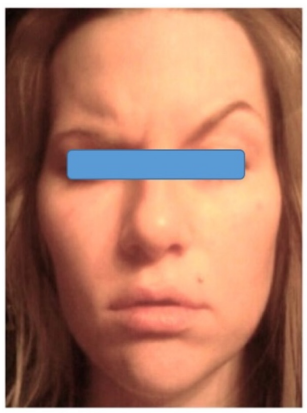

baseline

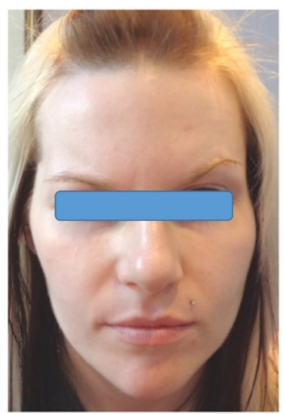

1 month

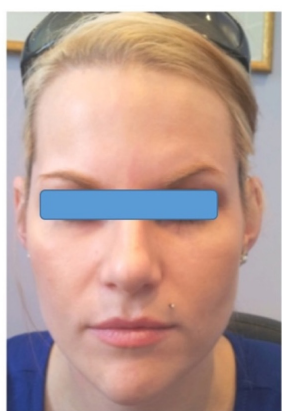

4 months

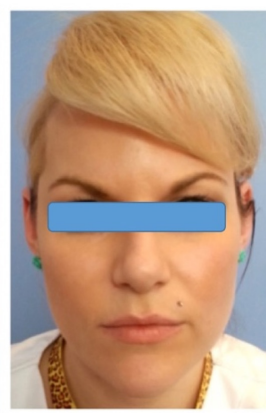

18 months

Figure 5. Patient K: Stem cell therapy for neuropathic pain and facial regeneration, timeline of her progress post stem cell treatment. Baseline pain intensity was $8-10 / 10$, at 1 mth 4/10, at 4 mths 0 - 2/10, 18 mths 0 - 1/10; excellent regeneration of the hemi-facial atrophy [Vickers ER. Neuropathic orofacial pain: Diagnosis and multimodal management. Medicine Today (Journal of the Royal Australian College of General Practitioners) 2015, 16(9), 16-24].

stem cell injections. Kmade a quick recovery and was able to go back to work and her everyday life with very minimal down time. Five years after the stem cell therapy $\mathrm{K}$ remains free of neuropathic pain and her facial appearance is normal. She regained her independence and continues to work with an improved mental health and quality of life.

\section{Conclusions}

For the patient seeking stem cell therapy, there are potential pre-existing psychological problems that must be addressed such as depression, anxiety, stress, unrealistic expectations, body image issues, loss of quality of life, fears and phobias. Unresolved issues can result in the patient being ineligible for a stem cell procedure. It is imperative that a counsellor performs an in-depth assessment of all patients seeking stem cell therapy. Mental health issues that have not been diagnosed or managed will result in poor outcomes. The patient with background psychosocial conditions must work with the counsellor and complete the necessary psychological treatment to produce a healthy mindset with realistic expectations in order to be considered eligible for stem cell therapy. This is similar to the doctor for the medical evaluation, and the scientist for validating laboratory protocols, as core members of the stem cell team. A dedicated and trained team comprising of diverse professionals who manage mental, psychological, medical, scientific and nursing issues will lead to improved patient outcomes from stem cell therapy for the purpose of regenerative medicine.

Regenerative medicine and the use of stem cell therapy will be major advances used for medical treatments of the future. It is important that these biotechnological advancements result in improvements to reverse the underlying disease process. However, it is also imperative that the patient improves psychologically to have an acceptable quality of life for his/herself and a return to normal engagement with the family and related social activities. From a government and 
socio-economic perspective, regeneration of the physical "self" should subsequently lead to adequate psychological daily functioning and meaningful employment. This can only be achieved when the psychological state is assessed and treated in conjunction with the medical state when considering stem cells for regenerative therapy.

\section{Conflicts of Interest}

The authors declare no conflicts of interest regarding the publication of this paper.

\section{References}

[1] Ankrum, J. and Karp, J.M. (2010) Mesenchymal Stem Cell Therapy: Two Steps Forward, One Step Back. Trends in Molecular Medicine, 16, 203-209. https://doi.org/10.1016/j.molmed.2010.02.005

[2] Batlle, E. and Clevers, H. (2017) Cancer Stem Cells Revisited. Nature Medicine, 23, 1124-1134. https://doi.org/10.1038/nm.4409

[3] Chen, B., Zhang, Z.K. and Wang, X. (2002) Factors Influencing Postoperative Satisfaction of Orthognathic Surgery Patients. International Journal of Adult Orthodontics and Orthognathic Surgery, 17, 217-222.

[4] Ryan, F.S., Barnard, M. and Cunningham, S.J. (2012) Impact of Dentofacial Deformityand Motivation for Treatment: A Qualitative Study. American Journal of Orthodontics and Dentofacial Orthopedics, 141, 734-742. https://doi.org/10.1016/j.ajodo.2011.12.026

[5] Rustemeyer, J., Eke, Z. and Bremerich, A. (2010) Perception of Improvement after Orthognathic Surgery: The Important Variables Affecting Patient Satisfaction. Oral and Maxillofacial Surgery, 14, 155-162. https://doi.org/10.1007/s10006-010-0212-2

[6] Türker, N., Varol, A. and Ogel, K. (2008) Perceptions of Preoperative Expectations and Postoperative Outcomes from Orthognathic Surgery: Part I: Turkish Female Patients. International Journal of Oral and Maxillofacial Surgery, 37, 710-715. https://doi.org/10.1016/j.ijom.2008.04.014

[7] Malterud, K. (2001) The Art and Science of Clinical Knowledge: Evidence beyond Measures and Numbers. Lancet, 358, 397-400. https://doi.org/10.1016/S0140-6736(01)05548-9

[8] Sawang, S., Oei, T.P.S. and Goh, Y.W. (2006) Are Country and Culture Values Interchangeable? A Case Example Using Occupational Stress and Coping. International Journal of Cross Cultural Management, 6, 205-219. https://doi.org/10.1177/1470595806066330

[9] Lovibond, P.F. and Lovibond, S.H. (1995) The Structure of Negative Emotional States: Comparison of the Depression Anxiety Stress Scales (DASS) with the Beck Depression and Anxiety Inventories. Behavioral Research and Therapy, 33, 335-343. https://doi.org/10.1016/0005-7967(94)00075-U

[10] Antony, M.M., Bieling, P.J., Cox, B.J., Enns, M.W. and Swinson, R.P. (1998) Psychometric Properties of the 42-Item and 21-Item Versions of the Depression Anxiety Stress Scales in Clinical Groups and a Community Sample. Psychological Assessment, 10, 176-181. https://doi.org/10.1037/1040-3590.10.2.176

[11] Raylu, N. and Oei, T.P.S. (2004) The Gambling Related Cognitions Scale (GRCS): Development, Confirmatory Factor Validation and Psychometric Properties. Addiction, 99, 757-769. https://doi.org/10.1111/j.1360-0443.2004.00753.x 
[12] Kamburoglu, H.O. and Ozguer, F. (2007) Postoperative Satisfaction and the Patient's Body Image, Life Satisfaction and Self-Esteem: A Retrospective Study Comparing Adolescent Girls and Boys after Cosmetic Surgery. Aesthetic Plastic Surgery, 31, 739-745. https://doi.org/10.1007/s00266-006-0133-5

[13] Noguti, J., De Moura, C.F.G., De Jesus, G.P.P., Da Silva, V.H.P., Hossaka, T.A., Oshima, C.T.F. and Ribeiro, D.A. (2012) Metastasis from Oral Cancer: An Overview. Cancer Genomics and Proteomics, 5, 329-335.

[14] Cash, T.F. and Fleming, E.C. (2002) The Impact of Body-Image Experiences: Development of the Body Image Quality of Life Inventory. International Journal of Eating Disorders, 31, 455-460. https://doi.org/10.1002/eat.10033

[15] Rankin, M., Borah, G.L., Perry, A.W. and Weyi, P.D. (1998) Quality of Life Outcomes after Cosmetic Surgery. Plastic Reconstruct Surgery, 102, 2139-2145. https://doi.org/10.1097/00006534-199811000-00053

[16] Wright, S., Yelland, M., Heathcote, K., Ng, S.K. and Wright, G. (2009) Fear of Needles, Nature and Prevalence in General Practice. Australian Family Physician, 38, 172-176.

[17] Sperry, S., Thompson, J.K., Sarwer, D.B. and Cash, T.F. (2009) Cosmetic Surgery Reality TV Viewership: Relations with Cosmetic Surgery Attitudes, Body Image, and Disordered Eating. Annals of Plastic Surgery, 62, 7-11. https://doi.org/10.1097/SAP.0b013e31817e2cb8

[18] American Psychiatric Association (2013) Diagnostic and Statistical Manual of Mental Disorders. 5th Edition, APA, Washington, DC.

[19] Garner, D.M. (2004) Eating Disorder Inventory-3 Professional Manual. Psychological Assessment Resources, Odessa, FL.

[20] Nair, B.P. and Baboo, G. (2017) Effect of Cosmetic Surgery on Body Image and Body Image Specific Quality of Life. Journal of the Indian Academy of Applied Psychology, 43, 157-161.

[21] Burke, N.L., Schaefer, L.M. and Thompson, J.K. (2012) Body Image. In: Ramachandran, V.S., Eds., Encyclopedia of Human Behaviour, Academic Press, New York. https://doi.org/10.1016/B978-0-12-375000-6.00066-5

[22] Soesta, T.V., Kvaleme, I.L., Roldb, H.E. and Skolleborg, K.C. (2009) The Effects of Cosmetic Surgery on Body Image, Self-Esteem, and Psychological Problems. International Journal of Surgical Reconstruction, 62, 1238-1244.

[23] Botton, M.A., Pruzinsk, T., Cash, T.F. and Persing, J.A. (2003) Measuring Outcomes in Plastic Surgery: Body Image and Quality of Life in Abdominoplasty Patients. Plastic and Reconstructive Surgery, 112, 619-625. https://doi.org/10.1097/01.PRS.0000070972.57000.08

[24] Roberts, M. (2014) Stem Cell Transplant Death What Went Wrong. Health Editor, BBC News Online. http://www.bbc.com/news/health-30194504 